\title{
Parental Flow and Positive Emotions: Optimal Experiences in Parent-Child Interactions and Parents' Well-Being
}

\author{
Anat Shoshani ${ }^{1}$ (D) Shachar Yaari ${ }^{1}$
}

Accepted: 27 June 2021 / Published online: 7 July 2021

(c) The Author(s), under exclusive licence to Springer Nature B.V. 2021

\begin{abstract}
Flow is a mental state of thorough absorption and concentration in an activity, in which intrinsic motivation and enjoyment are maximized, and the individual achieves optimal performance. This study investigated how daily flow experiences during parents' interactions with their children contribute to parental well-being. The Day Reconstruction Method was completed by 832 employed Israeli parents of children aged 2 to 12 , who reconstructed their experiences on three different working days over three weeks, and rated their levels of flow, as well as positive and negative affect for each experience. Participants also completed measures of subjective well-being and parental satisfaction and efficacy. The results indicated that parents' flow experiences during interactions with their children were positively related to parents' positive affect, self-efficacy and satisfaction, and greater subjective well-being. The findings underscore the importance for parental well-being of daily optimal experiences with their children.
\end{abstract}

Keywords Flow $\cdot$ Positive emotions $\cdot$ Parents $\cdot$ Children $\cdot$ Well-being $\cdot$ Satisfaction $\cdot$ Efficacy

\section{Introduction}

The time parents spend with their children is considered to be a critical parameter of optimal parenting (Musick et al., 2016). Beyond the amount of time spent, the kinds of activities and the quality of the time engaged in these interactions with children are thought to matter for parents to be seen as fully involved in the lives of their children (Milkie et al., 2010). Parents' subjective experiences of the time they spend with their children are also seen as important for their own well-being (Garey, 1999). However, there is scant data on the aspects of parent-child interactions that contribute to promoting a parental sense of efficacy, enjoyment, and well-being.

Positive psychology scholars have long espoused the importance of flow states and positive emotions for positive experiences. Flow reflects moments when people are so absorbed

Anat Shoshani

ashoshani@idc.ac.il

1 Baruch Ivcher School of Psychology, Interdisciplinary Center (IDC) Herzliya, P.O.Box 167, 46150 Herzliya, Israel 
in what they are doing that time appears to either fly by or stand still (Csikszentmihalyi, 1997). These are moments of ecstasy, pure enjoyment, and optimal experiences that make people feel good and fulfilled. People can feel flow when they are engrossed in a work project, involved in a leisure activity, running a marathon, playing the piano, or giving a speech (Csikszentmihalyi \& Csikszentmihalyi, 1992).

However, these flow or "in the zone" experiences, as researchers in the field call them (Csikszentmihalyi, 1997), may be much harder to achieve for parents during their busy and multi-task days. Studies have rarely addressed or documented the occurrence of flow within the parenting context. The scant literature on this subject has focused mainly on family characteristics that enable the flow experiences of children in the familial context (Csikszentmihalyi, 1997; Rathunde, 1988). However, fundamental research on flow experiences among the parents themselves is notably absent. Can the same ecstatic moments that occur when playing the piano, doing a puzzle, or playing football occur during the interaction between parent and child?

Similar to flow, positive emotions have long been identified as markers of people's overall happiness and well-being (Diener \& Seligman, 2004). Parenting is considered first and foremost to be an emotional experience. Raising a child involves more affection, joy, worry, and anger than most other daily activities (Negraia \& Augustine, 2020). Several studies have shown that parents' positive emotions reflect the health and quality of the parent-child relationship (e.g., Dix, 1991; Waters \& Sun, 2016). Nevertheless, the role played by positive emotions in parents' lives is poorly understood. Little is known about the positive emotions parents commonly experience during interactions with their children, when they occur, or their effects on parenting once aroused.

The present study aimed to systematically examine the associations between flow experiences and positive emotions in parenthood with respect to parental efficacy, satisfaction, and subjective well-being using a day reconstruction method (DRM; Kahneman et al., 2004). Parents were asked to systematically reconstruct their activities and the experiences of the entire preceding day retrospectively once a week (on different days) for three weeks and to provide affective and flow ratings of their experiences. We examined whether flow and positive emotion scores on the DRM related to parents' subjective well-being, parenting efficacy and satisfaction. We also examined the specific contribution of flow and positive affect in parent-child interactions to parental well-being beyond flow experiences and positive emotions in other contexts or activities such as work, interactions with friends, and intimate relations.

\subsection{Flow in Parenting}

In the literature, flow refers to an optimal subjective state of immersed concentration in which people's attention is deeply focused, distractions are minimized, and people attain an enjoyable give-and-take with their activity. In this optimal state, people often report that they forget about their daily problems, lose track of time, and feel enjoyment, a sense of control, and a sense that they are well-matched to the activities at hand (Csikszentmihalyi et al., 2014).

Csikszentmihalyi (1991) listed eight essential components that describe flow experiences. (1) merging of action and awareness (2) centering of attention (3) loss of selfconsciousness (4) distortion of time (5) clear goals (6) clear unambiguous feedback (7) control (8) autolectic enjoyment (i.e., intrinsically enjoyable). The first four components are aspects that describe being completely immersed in the experience. People become part 
of the experience and forget about their own awareness. They are not easily distracted and lose their sense of identity as time flies during the flow activity. The next four components are aspects of understanding the activity and being in control. There are no surprises during flow; people understand what comes next, and it is clear to them how well they are doing. They do not need external approval or reward in order to feel enjoyment during the activity. These eight components characterize flow as a state of being in the moment, and being a complete part of the experience one is immersed in.

Flow is usually experienced in conditions of high balanced challenges and skills (Csikszentmihalyi, 1990). In this experience, people typically feel optimally challenged and confident in their skills and abilities to control a situation. In cases of imbalance, when skills outweigh challenges, people may feel apathy, boredom, and relaxation, whereas when the challenges outweigh the skills, people may feel worry, anxiety and arousal (Csikszentmihalyi \& LeFevre, 1989).

At first glance, many parenting roles appear to be inherently contrary to flow experiences. Parenting is multi-determinant and complex task that is influenced by parenting practices and skills, but also by the parents' personalities, their children's personalities, and unpredictable situations and life circumstances (Wolfe, 2006). In addition, the growing participation of both parents in the labor market makes parenting more complex (Hart \& Hodson, 2006). Findings suggest that many parents feel that they do not have enough advice, support, or information about raising their children (Shepherd \& Roker, 2005). They tend to perceive their caring for their children as a strain and an obligation, as well as being a rewarding and meaningful task (Kerr et al., 2020). This may engender mixed feelings in parents toward parenthood that can make parenting clash with flow experiences but at other times be optimally suited to them.

In order to be in flow, parents must have the ability to 'be' with their child in the full sense of the word. However, many basic parental roles, such as supervision and regulation, socialization and guidance, protection and childcare preclude complete immersion in the situation (Nicholson et al., 2014). These parental functions situate the parent outside the experience and do not allow for complete absorption or a loss of reflective self-consciousness in the situation.

This does not change the fact that parents can be involved in a flow experience during their interactions with their children, especially since flow is often defined in the literature as a limited time of precious moments or hours of activities or interactions rather than a chronic state (Csikszentmihalyi, 1997). In the context of parent-child interactions, these moments can include a wide variety of exhilarating, pleasurable and deeply absorbing activities such as playing, watching a movie together, singing or dancing together, drawing or artwork.

Winnicot (1971) was the first to argue that an adult can "be" with a child in situations that have nothing to do with satisfying his or her needs or protecting the child. In particular, he sensed the importance of play in the development of the individual and claimed that play is the core of creativity, relationships, and mental health for parents and children (Winnicott, 1960). Here, we assumed that during playful interactions, in the 'potential space' (i.e., a space of play and creativity between the outer and inner worlds), where the self of the child and the parent meet absorbedly, the parent can enter into a state of flow together with the child that not only allows the parent to be in the moment but actually forget his/ her own worries and concerns.

Although parenting has not received much attention in the flow research field, a longitudinal study using an Experience Sampling Methodology (ESM) with parents after the birth of their first child suggests that taking care of the baby was frequently associated with 
a flow experience compared to other daily activities such as leisure, work, or media use. Parents' subjective experience of childcare was characterized by a sense of engagement, high challenge, positive affect, and intrinsic motivation (Delle Fave \& Massimini, 2004). Roughly $21 \%$ of the parents' self-reports of parenting activities were associated with optimal experiences, thus making daily childcare an opportunity for quality time, enjoyable resource investment, and personal fulfilment (Delle Fave et al., 2013).

However, the challenges and enjoyments of childcare seem to lessen as children get older. Raising older children (aged 2-14) was related to lower self-esteem and a lesser sense of competency in mothers compared to situations alone or with adults (Wells, 1988). A recent study on adolescents showed that $50 \%$ reported flow experiences in prosocial activities in the family context, especially when they were helping their parents (e.g. cooking together, doing gardening, or helping in the garage) (Mesurado \& de Minzi, 2014). The quality of the parent-child time therefore appears to be a significant factor when assessing parents' and familial well-being.

\subsection{Flow, Positive Emotions, and Parental Well-Being}

Many studies have found that a main predictor of adults' well-being is having and raising children (Azar, 2002). The term 'subjective well-being' refers to the psychological state of feelings of happiness, high positive affect, and life satisfaction (Diener, 2000). However, studies also show that although parenthood can be satisfying and joyful, it is simultaneously difficult and stressful. The literature on the association between parenting and subjective well-being is mixed, indicating that parenting can generate low well-being under certain circumstances and high well-being in others (Nelson et al., 2013). The complexity of the link between parenthood and well-being points to the potential benefits of understanding the experiences that enable parents to thrive in their important role and build their well-being (Waters \& Sun, 2016).

Previous studies have suggested that certain demographic and structural variables are linked with parental well-being. There is evidence, for example, that parental characteristics such as age, gender, race, education, marital status, employment status and income, as well as family composition such as number of children, their ages, and living arrangements are associated with parental well-being (Umberson, 1989). These associations may stem primarily from the fact that these variables impact the stressfulness or quality of the parent-child relationship, which in turn affect parental well-being (Nomaguchi \& Milkie, 2017).

Parenting in these studies, however, has been narrowly operationalized according to family composition or parental status which have tended to neglect the quality of the parent-child relationships and the ways in which this quality mediates the influence of parenting on parental well-being (Waters \& Sun, 2016). Although there is very little research examining flow in parent-child interactions and its contributions to parental well-being, there are some indirect data showing that arranging for sufficient quality time may be important for parental well-being. Quality time includes, for example, eating family meals together, reading together, playing, and working together on shared projects or homework (Milkie et al., 2010).

Garey's (1999) ethnographic study on employed mothers emphasized the importance of shared quality time with their children for mothers' well-being. Based on her interviews with mothers working in a large hospital in California, Garey (1999) concluded that mothers' well-being was highly dependent on their sense of the 'visibility' 
of their mothering. A key feature of this visibility involved maternal efforts to be engaged with the child in culturally defined quality time activities. For example, helping the child with homework was significant not only because it can promote academic success but also because such quality time was perceived as a symbol representing 'a good mother'. The mothers stated that for them, moments of 'being there' with their children, whether reading a book, eating dinner or playing games together acted as a symbol of good parenting (Garey, 1999). These daily activities were viewed as quality time because engaging in them is thought to enhance human capital, build close relationships with the child (Larson \& Richards, 1994), and increase positive emotions (Musick et al., 2016).

Positive emotions, the second facet of optimal daily experiences examined in this study, is a complex construct that encompasses a range of emotions that lead up to greater well-being (Frederickson, 2001). According the broaden-and-build theory (Frederickson, 2001) positive emotions such as happiness, love, and joy can broaden people's thought-action capabilities, which in the context of parenthood can contribute to building parents' enduring physical, emotional, and psychological resources. Studies have also found a significant positive correlation between flow experiences and positive affect (Cohn \& Fredrickson, 2010; Fredrickson \& Dutton, 2008). Recent studies on parents' daily emotions indicate that parenting is related to more positive emotions than non-parenting, and that the time parents spend with their children is perceived the happiest time of the day (Musick et al., 2016; Negraia \& Augustine, 2020; Nelson et al., 2014).

Negraia and Augustine (2020) found that parents' greater positive affect is activated during leisure and housework activities when children are present, with no significant differences between men and women. In addition, frequent positive emotions in parenting have been linked to parents' sense of efficacy in rearing their children (Nelson et al., 2013). Several studies implementing parents' daily diaries have shown that daily positive emotions, especially during parent-child interactions, buffered the negative immediate and long-term effects of stress on parents and diminished negative psychological states in parenthood (e.g., Doty et al., 2017; Ekas \& Whitman, 2010).

Research on parenthood and gender have reported mixed results. Some studies suggest that mothers and fathers are not uniquely different in their interactions with their children and their parental well-being (e.g., Fagan et al., 2014), whereas others claim that the experiences of fathers and mothers are different in ways that can impact their well-being (e.g., Musick et al., 2016; Nelson-Coffey et al., 2019). In one recent study, time diaries from women and men were collected before and after their child was born (Yavorsky et al., 2015). These diaries revealed a gender disparity in child care and housework which amounted to two hours additional work per day for mothers and $40 \mathrm{~min}$ per day for fathers. Other studies have found that fathers engage in much more leisure and play activities with their children than mothers (Musick et al., 2016; Yeung et al., 2001).

However, not all parent-child interactions correspond to an optimal experience characterized by flow or positive affect on the part of the parent. In addition, moments of shared quality time are often rare. A study that examined non-working mothers found that on average mothers spent half an hour a day playing with their babies even though they were physically with them the entire day (Clarke-Stewart, 1979). In this context, the ability to recognize the contribution of flow and positive affect experiences to the quality of parent-child relationships can contribute to greater parental well-being. 


\subsection{The Present Study}

The objective of this study was to explore the unique contribution of flow and positive affect during parent-child interactions in parents' daily experiences to their general subjective well-being and parenting satisfaction and efficacy. ${ }^{1}$ Parents' optimal experience with their children were operationalized in two ways. The first was based on flow theory, and predicted that parents' experiences would be the most positive when they were fully engaged in an enjoyable activity consistent with their skills to the point of losing their sense of time and everything else except the activity itself (Csikszentmihalyi, 1997). The second was based on the broaden-and-build theory of positive emotions (Fredrickson, 2001), and assumed that positive emotions during parent-child interactions would contribute to positive outcomes and a parental sense of efficacy, and that such consistent experiences would aggregate over time to produce an upward spiral of parental well-being.

Specifically, we hypothesized that parents who experienced flow and positive emotions during interactions more frequently with their children would report greater parenting selfefficacy and satisfaction, and higher subjective well-being. We also expected that parental efficacy and parental satisfaction would both mediate the relationship between positive affect and flow experiences with their children and subjective well-being. In addition, we controlled for positive and negative emotions and other daily flow experiences that are unrelated to parenting, to verify the unique contribution of flow and positive affect experiences with children to parental well-being.

These hypotheses were tested using the day reconstruction method (DRM; Kahneman et al., 2004) in which parents reconstruct their meaningful episodes or experiences from the previous day, on three different days over three weeks. For each episode, the participating parents were asked whether they were experiencing different dimensions of flow, and reported on their positive and negative emotions. Recalling episodes and events from the previous day is close enough in time for participants to accurately recollect their feelings without the memory bias that is often associated with global reports. For example, Robinson and Clore (2002) asked participants to recall their feelings and emotions in several different time frames (e.g. the "last few hours", the "last few days", the "last few months", etc.), and found that they were not susceptible to emotional recall bias for time periods shorter than the "last few weeks".

Furthermore, DRM reports on the previous day's emotions and activities have been shown to correspond to findings from traditional experience-sampling methods (ESM) that are based on momentary assessments at random occasions during the day (Kahneman et al., 2004).

We chose to use the DRM since it reduces the participants' burden, allows for the contiguous evaluation of episodes over the entire day rather than specific moments, and interrupts daily activities to a lesser extent. Each participant also completed measures of subjective well-being and parental satisfaction and efficacy on the last measurement point.

${ }^{1}$ This study was conducted before the COVID-19 pandemic, before disruptions to work and school. 


\section{Method}

\subsection{Participants}

The sample was composed of 832 employed parents in Israel (371 men, 461 women) with children between the ages of two and 12. The participants' mean age was 38.1 years $(S D=4.92), 78.6 \%$ were married and had 2.5 children on average $(S D=1.17)$. They were predominantly Israeli-born (96\%) and $97 \%$ of them were Jewish. In addition, $62.4 \%$ of the population reported middle socioeconomic status, 19.8\% high SES, and 17.8\% low SES. Participants worked an average of $32 \mathrm{~h}$ per week. Most participants had university degrees (an average level of education of 15.29 years, $S D=3.71$ ).

We recruited parents who spent at least three afternoons a week with their children. This criterion was designed to ensure that the participants spent enough time during the week with their children to complete the DRM about interactions with their children for the three days sampled. Participants were recruited through advertising in local areas and posts on social media (e.g., Twitter, Facebook, LinkedIn) and were compensated monetarily. One parent per household was eligible to participate. Exclusion factors were serious disease or illness, use of drugs and pregnancy, and parents who spend fewer than three afternoons a week with their children.

Sample size was determined by an a-priori power analysis conducted with G*Power software (Faul et al., 2007). A multiple regression power analysis (14 predictors) indicated that 194 participants were needed to detect a medium size effect $\left(f^{2}=0.15\right)$ with $\alpha=0.05$ and power $=0.95$. A larger sample size was recruited to maximize the power of the study.

\subsection{Measures}

Socio-demographic measures The participants completed a demographic questionnaire requesting background information on gender, age, religion, family status, number of children and their ages, education level, and income.

The Day Reconstruction Method (DRM; Kahneman et al., 2004) Participants were instructed to construct a diary of the previous day as follows: "Think of your day yesterday as a continuous series of episodes or scenes in a film. Give each episode a short title that will help you recall what happened during that specific episode (e.g., "made breakfast" "meeting at work" "wrote a report for work" "read a book to my child"). Write down the estimated time each episode started and ended and who the interaction was with (alone, spouse, child, colleague, etc.). Indications of the end of an episode can be ending one activity and starting another, going to a different place, or a change in the partner or people you were interacting with". Next, participants answered a number of questions including how they felt during the episode on a scale from 1(not at all) 7 (very much) indicating negative feeling as well as positive feelings (PANAS; Thompson, 2007) and how much flow they experienced using the Flow Experiences Scale (Schwartz \& Waterman, 2005; see below).

The activities in the DRM were coded by two independent coders who were blind to the hypotheses, using a coding scheme adapted from Milkie et al., 2010, and Kahneman et al., 2004. Each activity was first coded into one or more of 19 categories of activity type. Three activities included interactions with the children: interactive, child-care and interactive family. Interactive activities with children included quality activities with one or more children, such as reading and talking with the child, playing games outdoors or 
indoors, doing artwork, and helping with homework. Child-care activities included routine child care that could involve one or more children, such as bathing, clothing, or feeding, transportation, providing medical care, and putting them to bed. Interactive family activities included quality activities as a family as a whole, such as watching television together, going on vacation, visiting family members and friends, and going to the playground with the children. The remaining 16 categories included daily individual or social activities (i.e., working, housework, preparing food, eating, commuting, intimate relations and couple activities, praying/meditating, exercising, leisure personal activities, socializing, shopping, health care, napping, watching TV, phone/computer/ e-mail/ internet use, relaxing). In addition, each activity was coded for interaction partners (i.e., alone, children, spouse/ significant other, relatives, friends, acquaintances, colleagues/clients, strangers). Activities that fell into multiple categories were coded for each, resulting in multiple attributions. The affect and flow ratings of the activities were averaged into total scores for each participant, grouped by activity type and by interaction partners. The coders were trained on the coding procedure to $95 \%$ reliability before conducting the actual study using 117 DRM reports of parents who participated in a pilot study. The inter-rater reliability analysis indicated high agreement between the coders (kappa $=0.98$ for activity type, and kappa $=0.99$ for interaction partners). Disagreements were resolved through discussion.

The Flow Experiences Scale (Schwartz \& Waterman, 2006) was used to measure the participants' flow state during the episodes listed in the DRM. Flow was measured using an eight-item scale based on Csikszentmihalyi's (1990) elements of flow where each item corresponds to one element. The elements were: (1) clear goals, (2) loss of self-consciousness, (3) control, (4) distortion of time, (5) clear unambiguous feedback, (6) centering of attention (7) forgetting personal problems, and (8) merging of action and awareness. Each item was rated on a seven-point scale ranging from 1(not at all) 7 (very much). Items were averaged to calculate flow per episode. The Cronbach's $\alpha$ for the total scale was 0.71 .

Shortened Positive and Negative Affect Schedule (PANAS-SF; Thompson, 2007) is a 10-item version of the Positive and Negative Affect Schedule (Watson et al., 1988) with 5-item positive affect (inspired, alert, determined, attentive, and active) and 5-item negative affect (upset, hostile, afraid, nervous, and ashamed) subscales. The participants were instructed to rate how much they felt each emotion during the DRM episodes from 1 (very slightly or not at all) to 7 (very much). The PANAS scale was converted into a 7-point Likert scale in the DRM to have ratings on the same scale for flow and emotions. On the fourth measurement point the participants were asked about the level of their positive and negative emotions during the previous month as indicators of their global subjective well-being, using the original 5-point scale. Scores for Positive Affect (PA) and for Negative Affect (NA) were summed. The PANAS-SF demonstrated good reliability in this study with a Cronbach's alpha of 0.85 for positive emotions and 0.78 for negative emotions.

Satisfaction with Life Scale (SWLS; Diener et al., 1985) The SWLS is a 5-item selfreport scale that assesses overall satisfaction with life (e.g., "The conditions of my life are excellent" "In most ways my life is close to my ideal"). Responses were provided on a fivepoint Likert scale from 1 (strongly disagree) to 5 (strongly agree). Scores on the five items were averaged to yield a total life-satisfaction score. The Cronbach's alpha in this study was 0.83 .

The Parenting Sense of Competence (PSOC) (Gibaud-Wallston \& Wandersman, 1978) is a self-report scale comprised of two subscales designed to assess parents' self-efficacy in their parenting role (e.g., "Being a parent is manageable, and any problems are easily solved"), and parenting satisfaction (e.g., "Even though being a parent could be rewarding, I am frustrated now while my child is at his/her present age."). The scale consists of 
17 items that are rated on a 6-point Likert scale ranging from 1 (strongly disagree) to 6 (strongly agree). Negative items were reversed so that high total scores indicated positive experiences of parenting. The scale had good internal consistency in this study $(\alpha=0.84)$.

\subsection{Procedure}

After receiving authorization from the institutional review board of the Interdisciplinary Center Herzliya, working parents were recruited to participate in the study. Eligibility and exclusion criteria were verified on the basis of a short questionnaire administered on the research web platform. The participants were asked to sign a consent form and were promised full anonymity. The study consisted of four different measurement points. Each participant completed three $24 \mathrm{~h}$ periods of DRM assessment during the early morning hours on working days regarding the previous day. The DRM assessment was completed online via Qualtrics survey software links that were sent by research assistants to the participants by email or via the Whatsapp messaging platform. The three DRM assessment days were separated by a minimum of 5 days, and were scheduled within an 18-day period. The fourth measurement point was at a maximum of 7 days after the last DRM assessment day, and included the psychological well-being questionnaires and the parenting sense of competence scale.

\subsection{Statistical Analyses}

The DRM provided a sequence of daily activities with associated flow and affect ratings and activity duration. The activities were categorized according to activity type (e.g., childcare activities, working, commuting), and interaction partners (e.g., alone, children) by the two independent coders. Flow, positive affect, and negative affect ratings for each category were averaged within and then across participants. First, single scores were calculated for positive affect, negative affect, and flow for each category per participant. The mean hours per day for each category per participant (i.e. the mean duration of engaging in a particular activity) was also calculated. Given that the activities varied in type and number across subjects (i.e., not every participant reported data in each category on each measurement), the mean scores per category were based on participants for which data existed at least once during the three DRM measurement points. Participants with no time at all spent doing a particular activity were not included in the average scores for this category. Then, the person level scores were averaged to total flow, affect, and activity duration scores for each category across participants.

All statistical analyses were performed using the SPSS 25 and AMOS 25 statistical packages. First, Pearson correlation tests were used to evaluate the relationship between flow and affect scores in all parent-child activities (child care, leisure, and family activities) and parenting and well-being factors. Then, planned comparisons using paired-samples t-tests with a Bonferroni correction were conducted to test for differences in positive affect, negative affect and total flow scores between activities that involved children and the most frequent main activities without them.

Next, a set of step-wise multivariate regression models were conducted. These analyses examined the predictive effects of the socio-demographic background variables, flow experiences, and affect levels during solitary or social activities without children, and during activities with children on parents' subjective well-being, and parental satisfaction and efficacy. The child-related factors (i.e., flow and affect ratings during activities in which 
the children were the interaction partners) were entered in the second step to assess their unique contribution to the outcome variables. In order to ensure that multicollinearity problems in the regression models were avoided, variance inflation factor (VIF) and tolerance tests were carried out.

Then, a structural equation model (SEM) was used to examine the relationships between flow and positive affect in parent-child activities on parents' subjective well-being, with parental efficacy and satisfaction as mediators. The bootstrapping method was applied to verify mediation effects, using 5,000 bootstrapped samples and $95 \%$ bias-corrected confidence intervals. A number of popular model fit indices were used to evaluate the fit of the model to the data including the chi-square statistic, comparative fit index (CFI), normed fit index (NFI), root mean square error of approximation (RMSEA), and the standardized root mean square residual (SRMR). The levels of CFI and NFI $\geq 0.90$, RMSEA $\leq 0.10$, and SRMR $\leq 0.08$ were acceptable (Kline, 2010).

\section{Results}

\subsection{Descriptive Statistics}

The means, standard deviations, and Pearson correlations for the independent and dependent variables are presented in Table 1. Skewness and kurtosis coefficients indicated that the data satisfied the assumption of a normal distribution. The flow and positive affect experiences of parents with their children were significantly related to parents' satisfaction, efficacy and well-being. Mothers reported more positive emotions and fewer negative emotions during interactions with their children, and greater parental satisfaction than fathers. Age was related to greater parental satisfaction. The number of children was significantly correlated with parental and life satisfaction.

Table 2 presents the affect and flow ratings of the situations reported in the three cycles of the DRM, grouped by activity type (e.g., working, exercising, eating) or by interaction partners. Respondents reported an average of 13 episodes per day. The values shown in the table are the average participants' ratings and standard deviations of specific activities, and the mean hours spent on each activity per day. To examine the nature of the daily differences in flow and affect between the most frequent activities, planned comparisons using paired-samples $t$-tests were carried out for each dependent measure. To correct for all 50 comparisons, we computed a corrected Bonferroni alpha $(\alpha=0.05 / 50$, corrected $\alpha=0.001)$.

Participants reported more flow and positive emotions while playing and doing activities with their children than in leisure personal activities (flow: $t(104)=3.34, p=0.001$; positive emotions: $t(104)=4.12, p<0.001$ ), working (flow: $t(831)=2.62, p=0.009$; positive emotions: $t(831)=15.35 p<0.001$ ), or socializing (flow: $t(623)=6.24, p<0.001$; positive emotions: $t(623)=5.50, p<0.001)$. However, praying/meditating, $t(100)=4.45$, $p<0.001$, and exercising, $t(217)=5.24, p<0.001$, were associated with greater flow than interacting with children. Situations at work were characterized by relatively high levels of negative emotions that were significantly greater than during interactions with children, $t$ $(831)=9.50 p<0.001$.

Taking care of children yielded a significantly lower level of flow $t(831)=9.70$ $p<0.001$, and positive emotions, $t(831)=19.64, p<0.001$, and higher negative emotions, $t(831)=12.17 p<0.001$, compared to playful interactions with them. The participants also 


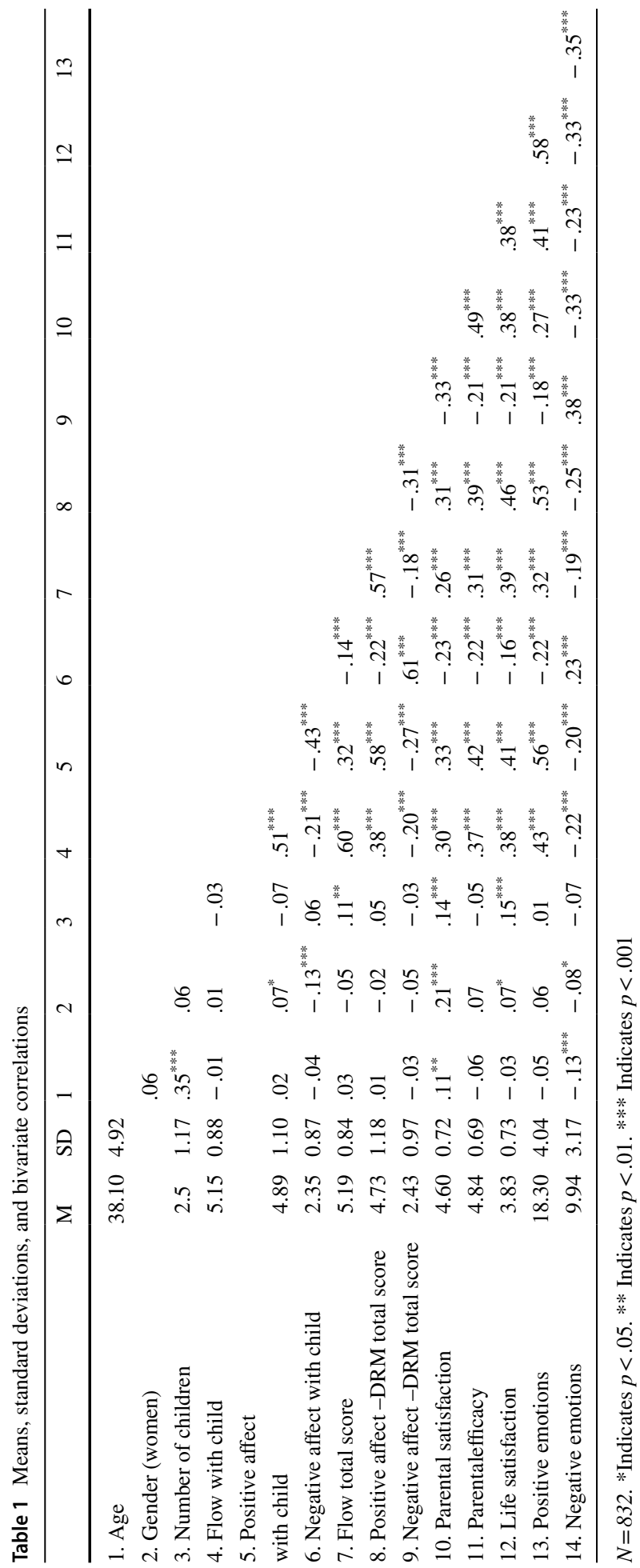


Table 2 Mean flow and affect ratings by situation

\begin{tabular}{|c|c|c|c|c|c|c|c|c|}
\hline & \multirow{2}{*}{$\begin{array}{l}\text { Number of } \\
\text { participants } \\
\text { reporting } \\
\mathrm{n}\end{array}$} & \multicolumn{2}{|l|}{ Flow } & \multicolumn{2}{|l|}{ PA } & \multicolumn{2}{|l|}{ NA } & \multirow{2}{*}{$\begin{array}{l}\text { Mean } \\
\text { hours per } \\
\text { day }^{*}\end{array}$} \\
\hline & & Mean & $\mathrm{SD}$ & Mean & SD & Mean & SD & \\
\hline \multicolumn{9}{|l|}{ Activities ${ }^{* *}$} \\
\hline Praying/meditating & 101 & 5.97 & 0.36 & 5.59 & 0.33 & 1.84 & 0.14 & 1.1 \\
\hline Exercising & 218 & 5.86 & 0.65 & 5.95 & 0.70 & 1.64 & 0.62 & 1.2 \\
\hline $\begin{array}{l}\text { Interactive activities with } \\
\text { children }\end{array}$ & 832 & 5.58 & 1.05 & 5.70 & 1.17 & 1.97 & 0.73 & 1.3 \\
\hline Working & 832 & 5.44 & 1.10 & 4.59 & 1.66 & 2.50 & 1.24 & 7.0 \\
\hline $\begin{array}{l}\text { Intimate relations/activities with } \\
\text { spouse }\end{array}$ & 124 & 5.41 & 1.25 & 5.49 & 1.34 & 1.80 & 0.74 & 1.2 \\
\hline Preparing food & 832 & 5.31 & 1.10 & 4.46 & 1.35 & 2.45 & 0.78 & 1.2 \\
\hline Leisure activity & 105 & 5.30 & 1.21 & 5.23 & 1.38 & 2.04 & 0.90 & 1.5 \\
\hline Socializing & 624 & 5.25 & 1.12 & 5.35 & 1.30 & 2.08 & 0.93 & 1.5 \\
\hline Napping & 374 & 5.16 & 0.98 & 4.27 & 1.20 & 2.54 & 1.11 & 1.0 \\
\hline Shopping & 586 & 5.13 & 1.12 & 4.33 & 1.56 & 2.34 & 0.98 & 1.4 \\
\hline Health care & 95 & 5.07 & 0.52 & 4.46 & 0.93 & 3.01 & 0.87 & 1.1 \\
\hline Child-care activities & 832 & 5.07 & 1.07 & 4.57 & 1.63 & 2.51 & 1.07 & 1.5 \\
\hline Watching TV & 782 & 5.03 & 0.98 & 4.83 & 0.97 & 2.16 & 0.67 & 1.7 \\
\hline $\begin{array}{l}\text { On the phone/computer/e-mail/ } \\
\text { internet }\end{array}$ & 832 & 5.01 & 1.20 & 4.37 & 1.54 & 2.22 & 1.02 & 1.3 \\
\hline Family activity & 832 & 4.99 & 1.26 & 5.21 & 1.34 & 2.08 & 0.98 & 1.6 \\
\hline Housework & 832 & 4.98 & 1.17 & 3.95 & 1.62 & 2.63 & 1.27 & 1.2 \\
\hline Eating & 832 & 4.90 & 1.10 & 4.93 & 1.36 & 2.06 & 0.85 & 1.2 \\
\hline Commuting & 741 & 4.86 & 1.03 & 4.47 & 1.48 & 2.96 & 1.24 & 0.9 \\
\hline Relaxing & 67 & 4.37 & 0.87 & 4.22 & 0.77 & 2.12 & 0.30 & 1.0 \\
\hline Total & & 5.22 & 1.18 & 4.75 & 1.60 & 2.32 & 1.12 & 1.6 \\
\hline \multicolumn{9}{|l|}{ Interaction partners } \\
\hline Friends & 582 & 5.42 & 1.11 & 5.35 & 1.31 & 2.10 & 0.94 & 2.2 \\
\hline Acquaintances & 192 & 5.39 & 1.07 & 5.06 & 1.29 & 2.40 & 1.17 & 1.0 \\
\hline Strangers & 615 & 5.39 & 0.98 & 4.76 & 1.60 & 2.50 & 1.31 & 0.8 \\
\hline Colleagues/clients & 785 & 5.35 & 1.03 & 4.73 & 1.48 & 2.58 & 1.27 & 5.5 \\
\hline Alone & 832 & 5.17 & 0.98 & 4.36 & 1.37 & 2.41 & 1.06 & 3.2 \\
\hline Children & 832 & 5.15 & 0.88 & 4.89 & 1.10 & 2.35 & 0.87 & 2.4 \\
\hline Relatives & 334 & 5.06 & 1.14 & 4.92 & 1.57 & 2.21 & 1.16 & 1.2 \\
\hline Spouse/significant other & 640 & 5.02 & 1.13 & 4.76 & 1.40 & 2.38 & 1.09 & 2.3 \\
\hline
\end{tabular}

$N=832$; $*$ The average amount of time participants who did the activity spent doing it

**Situations for which the respondents reported multiple interaction partners or activities were included in each of the corresponding categories

reported greater flow and positive emotions while interacting with their children, socializing, exercising, and praying/meditating compared to doing housework tasks and during eating, commuting, and passive relaxing without engaging in any special activity (all $p s<0.001)$. 
Participants experienced more flow and positive emotions in interactions with their close friends than with their children (flow: $t(581)=6.16, p<0.001$; positive emotions: $t(581)=4.58, p<0.001$ ), relatives (flow: $t(333)=3.84, p<0.001$; positive emotions: $t$ $(333)=3.37, p=0.001$ ), or spouses (flow: $t(581)=6.64, p<0.001$; positive emotions: $t$ $(581)=6.53, p<0.001)$. Parents spent an average of $1.3 \mathrm{~h}$ a day playing or doing activities with their children, $1.5 \mathrm{~h}$ per day taking care of their children (e.g., driving them to classes, putting them to bed) and at least $1.2 \mathrm{~h}$ a day on household chores (see Table 2).

\subsection{Flow and Positive Affect in Daily Experiences and Psychological Well-Being}

Hierarchical regression analyses were used to examine the predictive effects of the sociodemographic variables (i.e., gender, age, socioeconomic status, family status, number of children), flow experiences, positive affect and negative affect during solitary, social (i.e., activities in which other people were involved), and child-related activities (i.e., activities in which children were the interaction partners) on the three dimensions of psychological well-being and parental satisfaction and efficacy. As shown in Table 3, the variables that related to individual or social activities were entered in Step 1, and those related to activities with the child in Step 2 to examine their unique contribution to parents' well-being over and beyond the influence of other daily personal and social activities. The results of the two steps of the hierarchical regression analyses are shown in Table 3 . The tolerance and VIH tests indicated that multicollinearity was not a concern in the regression models. All the VIF values were less than 10 (ranged from 1.04 to 2.19) and the tolerance values ranged from 0.46 to 0.96 .

The first step of the analyses showed that positive affect in individual activities was significantly related to life satisfaction, general positive affect, parenting satisfaction and efficacy. Social activity-related factors in terms of flow and positive emotions were found to be significant predictors of psychological well-being. Women had higher life satisfaction and positive emotions, fewer negative emotions, and greater parenting satisfaction and efficacy than men. Participants' age was negatively associated with life satisfaction and parental efficacy. The number of children was associated with greater life satisfaction but lower parental efficacy. These factors explained $17-27 \%$ of the variation in the well-being and parental variables.

The second step of the analyses revealed that flow and positive affect experiences with one's children were significantly related to the participants' well-being and sense of efficacy and satisfaction from parenting. The second set of factors contributed to explaining $7 \%$ of the variance in life satisfaction, $15 \%$ of the variance in positive affect, and $6-8 \%$ in the variance in parenting satisfaction and efficacy.

\subsection{Mediation Effects of Parental Efficacy and Satisfaction}

Next, we examined whether the associations of flow and positive affect experiences with children on parents' subjective well-being was mediated by parental sense of efficacy and/or satisfaction. To do so, a mediation analysis was conducted, using 5000 bootstrap samples with AMOS software (version 25.0). The Structural Equation Modeling (SEM) included the positive affect and flow rates in the participants' interactions with their children as the independent variables, parental efficacy and satisfaction as sequential mediators, and a latent factor of subjective well-being made up of life satisfaction, positive emotions and negative emotions as the dependent variable. 


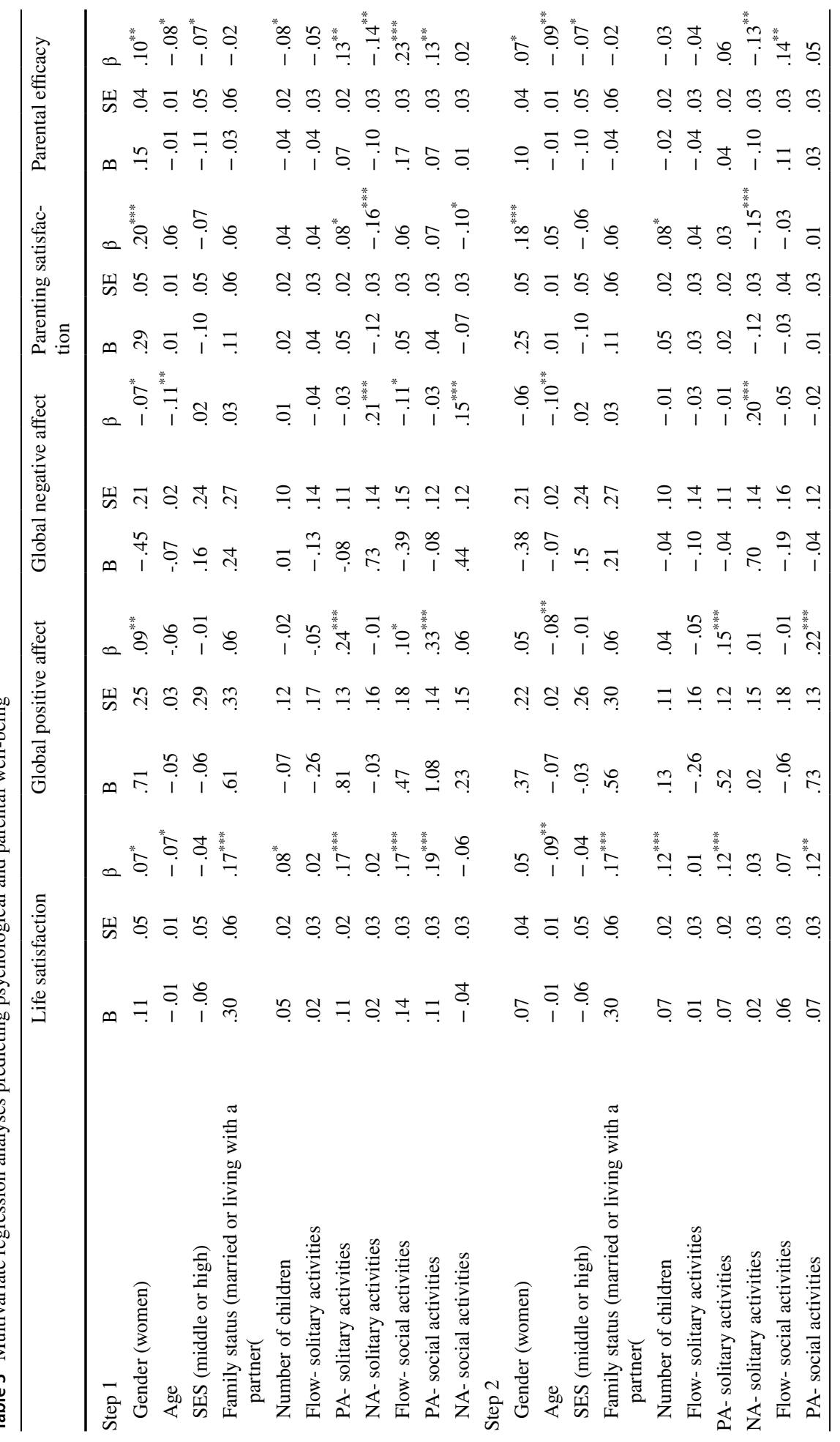




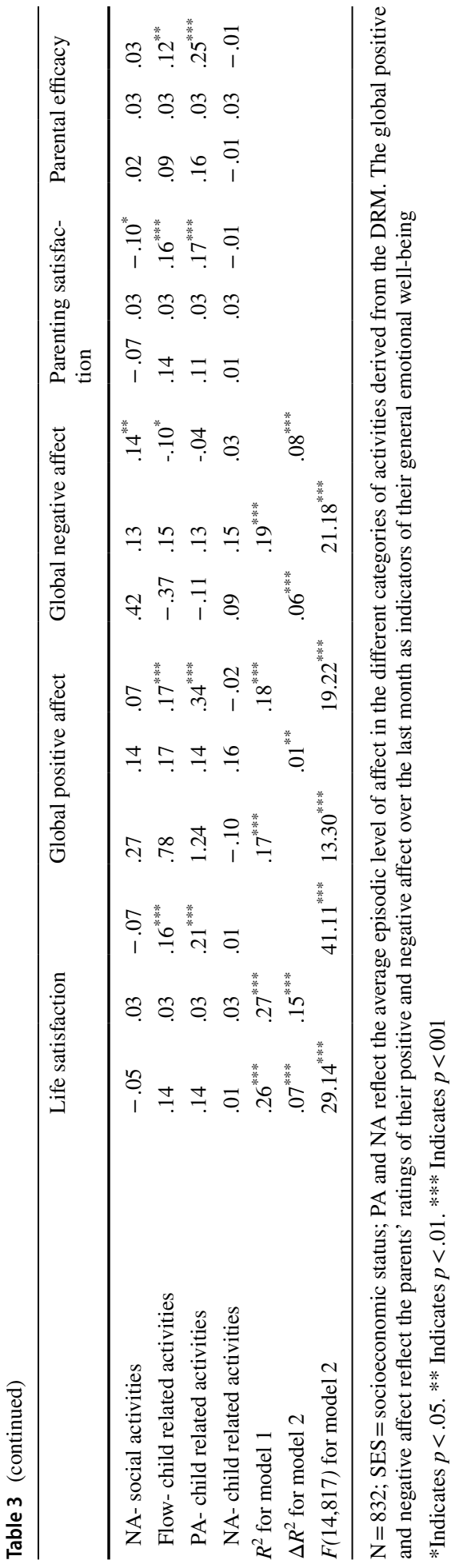




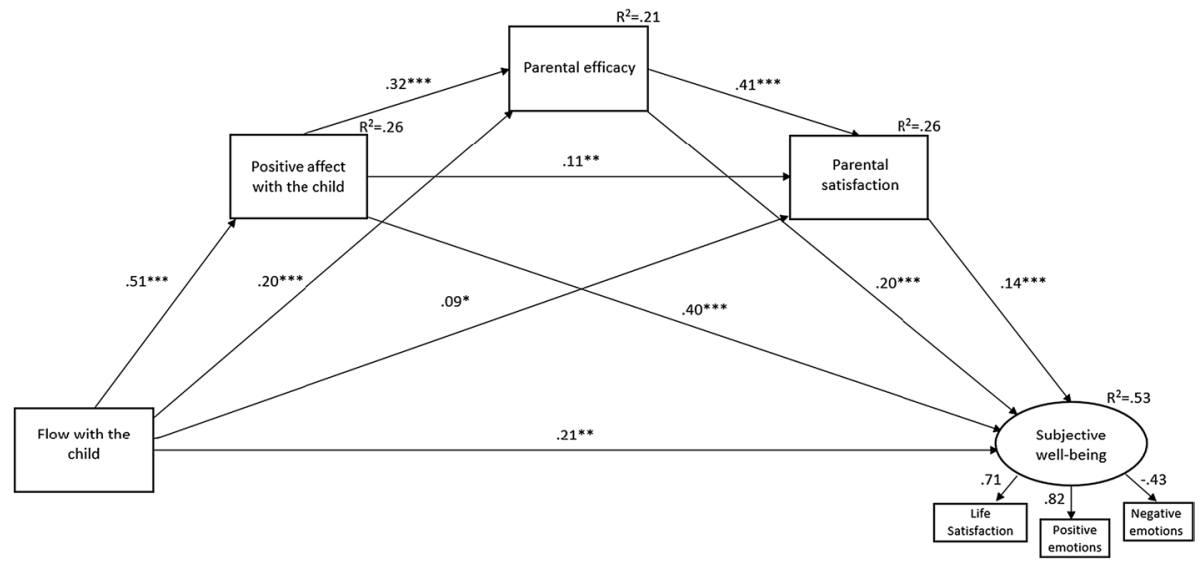

Fig. 1 A serial- multiple mediation model for the relationships between flow experiences of parents with their children and their subjective well-being

As expected, the analysis indicated a serial mediation whereby parental efficacy and parental satisfaction sequentially mediated the relationship between flow experiences with children and subjective well-being $(B=0.07, S E=0.02,95 \% \mathrm{CI}=0.0038-0.108 . p<0.001)$, and between positive affect in interactions with children and subjective well-being $(B=0.10, S E=0.02,95 \% \mathrm{CI}=0.067-0.145, p<0.001)$. The reversed model $(\mathrm{M} 1=$ parental satisfaction, M2 = parental efficacy) was weaker. However, positive affect was also found to be a significant mediator in the relationship between flow experiences and parental efficacy $(B=0.16, S E=0.02,95 \% \mathrm{CI}=0.120-0.207, p<0.001)$ and satisfaction $(B=0.21$, $S E=0.03,95 \% \mathrm{CI}=0.152-0.257, p<0.001)$. The associations of flow experiences with positive affect, parental efficacy and satisfaction and well-being were still significant after controlling for the mediators, suggesting partial mediation by the included variables (see Fig. 1). The total indirect effect of flow experiences with the child on well-being was significant $(B=0.32, S E=0.03,95 \% \mathrm{CI}=0.262-0.382, p<0.001)$. The model yielded an acceptable fit to the data $(\chi 2=90.91, d f=8, p<0.001 ; R M S E A=0.11 ; S R M R=0.04 ; C F I=0.95$; $N F I=0.95)$. In sum, three sequential mediators of positive affect, parental efficacy, and parental satisfaction partially mediated the relationship between parental flow experiences with their children and their subjective well-being.

\section{Discussion}

The present study focused on parents' daily experiences of flow and positive emotions during the time they spent with their children, in the attempt to identify how the nature of parent-child interactions shapes the experience of parenting and contributes to differences in parental subjective well-being.

The results suggest that parents' interactions with their children were associated with greater flow and positive emotions compared to almost all of the other activities the parents engaged in during the day. These findings are consistent with previous studies indicating that interactions with children rank near the top of the list of daily enjoyable activities (Delle Fave \& Massimini, 2004; Delle Fave et al., 2013; Dow \& Juster, 1985; 
Flood, 1997). Parents experienced more positive emotions and flow when they were playing and doing activities with their children than during working, socializing, interacting with their spouses, or performing leisure activities. The only exceptions were praying, meditating, or exercising that were associated with higher levels of flow. Flow experiences also occurred more often during work activities but positive emotions were lower and negative emotions were higher in work settings compared to interactions with children.

These findings suggest that of all the activities parents engage in during their lives, parenting presents a considerable opportunity for flow to occur. In fact, parenting seems to correspond to the characteristics of flow as defined by Csikszentmihalyi (1991) in many ways. Parenting is undoubtedly complex and is perceived as one of the most challenging tasks for adults (Liss et al., 2013). It requires high individual and interpersonal skills but at the same time, is accompanied by intrinsic motivation, in that many parents feel that parenting is the most important thing they do (Matusicky \& Russell, 2009). In addition, parenting fosters engagement and commitment independently of approval or extrinsic rewards. The types of activities parents engage in with their children such as playing, doing outdoor activities, or reading stories seem to have a great potential for a flow experience.

The results also provided support for the assumption that children are not just a source of immediate flow, but rather contribute to positive emotions and subjective well-being in parents' lives more generally. Many parents depict children as "bundles of joy" (Nelson et al., 2014). Our findings showed that parents' play and leisure activities with their children constituted a continuous source of happiness in their lives. These findings dovetail recent findings that parents feel high enjoyment and positive emotions during the time they spend with their children (e.g., Musick et al., 2016; Nelson et al., 2013) and challenge widely held assumptions of the popular media (Senior, 2014) and prior studies (Bianchi \& Mattingly, 2003; Bittman \& Wajcman, 2000; Kahneman et al., 2004) that children are a source of reduced positive emotions and well-being.

This disparity in perceptions may be due to the differences in modes of assessment of parents' well-being in the literature. Previous studies have suggested that the assessment of well-being linked specifically to daily activities is more reliable than relying on global indicators of subjective well-being (Kahneman \& Krueger, 2006; Musick et al., 2016). Daily or momentary assessments of parental well-being shift the emphasis from how life circumstances or parental status contribute to general subjective well-being to what contextual aspects shape it from moment to moment. Our findings clearly indicate that parental daily optimal experiences of "being with the child" contribute to parents' sense of efficacy and overall well-being.

More specifically, however, these relationships illustrate the unique contribution of flow and positive affect during activities with children to parents' general well-being beyond any other flow or enjoyable experiences during the day without their children. Thus, optimal experiences of flow and positive emotions in parent-child interactions emerged as salient factors in predicting parental well-being. There are several possible explanations for these associations. Frequent daily enjoyable activities with the child such as playing together, having a relaxing walk in the park, or watching a favorite TV serial can provide a source of closeness and love and invoke feelings of wonder, playfulness, pride and joy (Edin \& Kefalas, 2011; Nelson et al., 2013). In addition, some of these activities are carefully chosen by the parents to facilitate skills that may be valuable for the child (for example, teaching the child or providing a moral education), and thus provide opportunities for the parents to feel meaning, purpose, and fulfillment (Garey, 1999). In addition, because having children may be fulfilling a significant 
life goal for many parents, positive experiences of parenting with their children may be associated with greater happiness and life satisfaction in general (Barnett \& Hyde, 2001).

Markowitz et al. (2014) suggested that forming and maintaining close interpersonal relationships can create a "relational flow." In this state, close relationship partners are absorbed and engaged in the relationship itself, and the actual activity may be less important than the experience of being together. Relational aspects such as enjoyment, listening, attention, cooperation and solidarity may play a role in reaching a state of flow within the relationship context of parents with their children.

In addition to being a source of positive affect themselves, children may also increase positive emotions by injecting a wide array of experiences into their parents' daily lives. Previous studied have demonstrated that variety is a significant predictor of subjective well-being (Sheldon \& Lyubomirsky, 2012). The variety and intensity of positive experiences with the child can infuse surprise, playfulness, and novelty into the parents' lives, alleviate boredom or stress, and increase opportunities for flow, engagement and hedonic pleasure.

However, it cannot be ignored that raising children involves both joys and challenges (Nomaguchi \& Milkie, 2017), as also demonstrated in the current findings. Situations in which parents reported that they were taking care of their children, performing household chores, or doing onerous tasks, such transporting children and preparing food were associated with more negative emotions, fewer positive emotions and flow, and were more likely to involve frustration.

The flow experience relies heavily on the individual's perception of high challenge and high skill for a given activity (i.e., the skill-challenge balance) (Csikszentmihalyi, 1990). Thus, the "goodness of fit" between parental skills and challenges emerged as an essential factor in parents' ability to the experience flow. From this standpoint it is not surprising that fewer optimal experiences and more negative emotions were reported for daily child-care activities, some of which are very challenging and frustrating, whereas others are very simple and unrewarding.

Conversely, "pure" leisure interactions with children, such as sports, talking and reading with children, or engaging in hobbies together were positively related to flow experience and positive emotions. However, such quality-time activities were relatively infrequent and brief during the day, and were estimated in this study at $1.3 \mathrm{~h}$ per day. These findings imply that the moments of pleasure and happiness parents experience may be offset by the many moments of tasks, chores, and responsibility that are part and parcel of parenthood, and underscore the importance of increasing the quality and quantity of time that parents and children spend together to foster their well-being.

The findings for gender differences in parental well-being showed that mothers reported greater subjective overall well-being than fathers. In addition, mothers reported more positive affect and less negative affect when they were interacting with their children, and higher levels of satisfaction from parenting. This discrepancy between fathers' and mothers' parental well-being may be due in part to an unequal division of labor in the family and work domains. Although many couples today share labor outside and inside the home (Galinsky et al., 2009), women still devote more time to household tasks and child care in many cultures (Yavorsky et al., 2015). However, although mothers bear more the brunt of child care (Nomaguchi \& Milkie, 2017), they still have much more time with their children and possibly more opportunities to engage in enjoyable and meaningful activities with their children. 


\subsection{Study Limitations}

A number of limitations to this study should be noted. Although it was based on daily time diaries from men and women, it was driven by data from only one respondent per household. Collecting data from couples would allow for further exploration of the amount and quality of time parents spend with their children. In addition, because the study design was a short-term and cross-sectional (over only one month), we could not examine changes in parents' well-being during different parenting periods and transitions.

The DRM assessment in this study does not provide measures such as child behavior, relationship quality, emotional strain, and social support, which may moderate the links between daily experiences and parental well-being. Likewise, other qualitative factors related to parenting (e.g., parenting styles, involvement and warmth, emotional expression, self-regulation) were not explored but are important to consider in future studies. In addition, the DRM depends on retrieving information about the previous day that is filtered by memory, perspective, and self-reflection. Despite our efforts to reduce memory bias by using a short time frame of 12 to $24 \mathrm{~h}$ from the actual time of the events, this is still a possible shortcoming of this method. Furthermore, in this study the reliabilities of the person-level scores were uneven, given that some individuals engaged in some activities more than other individuals, and contributed more data to specific activity estimates, thus making them more reliable than others. However, the uneven reliabilities resulting from the nested data structure in this study were not corrected or adjusted analytically. Future research should employ multilevel models to overcome this shortcoming.

The possible conceptual overlaps between the independent and dependent variables in this study, such as potential relationships between episodic affect and general emotional well-being or parenting sense of competence, could have inflated the proportions of the explained variance in this study. In addition, the items on the Shortened Positive and Negative Affect Schedule could also contribute to the correlations. The positive affect items that examined activation, inspiration, determination, and attentiveness overlapped to some extent with aspects of flow. Negative affect items such as being upset or anxious could coincide with aspects of parental efficacy. Finally, the study relied on self-report measures on parenting and well-being, which may elicit socially desirable answers. Future studies would benefit from incorporating different informants (e.g., child, spouse) that could contribute to a more comprehensive assessment of parental well-being.

\subsection{Conclusion and Implications}

The findings indicate that the time parents interact with their children plays a central role in parents' sense of efficacy and well-being. The results also imply that it is not merely the amount of time that matters but also how that time is spent. More specifically, parents who experience engagement, enjoyment, absorption, focus, intrinsic motivation, and involvement in daily interactions with their children during leisure, child care, or family interactions are more likely to feel satisfied with parenthood and to experience greater well-being. On the other hand, parent-child interactions that are rushed, stressful, or fragmented may not provide the opportunities for parents and children to experience flow or to realize the full positive potential of parent-child interactions.

Is it possible to teach parents to be in flow? Experimental studies suggest that parents can intentionally increase their well-being and the frequency of positive affect by practicing 
a wide range of positive activities (Lyubomirsky \& Layous, 2013; Waters \& Sun, 2016). Parents may be able to learn to prioritize activities when they are intrinsically motivated to engage in them with their children. These activities should be ones that are enjoyable, whether playing chess, dancing, going on a trip, or running together, and are characterized above all by a spontaneous, deep involvement with the activity at hand. These include activities in which parents feel skilled and their attention is focused, where daily concerns and worries are temporarily suspended (Csikszentmihalyi, 1990).

Consequently, increasing parents' daily moments of flow and positive emotions by increasing awareness and suggesting appropriate interventions are likely to have benefits not only for parental well-being but possibly also for their children. Studies suggest that parents' subjective well-being is associated with specific positive parenting behaviors and with positive social, emotional, and academic outcomes for their children (e.g., Dix, 1991). Thus the present study may be useful to parents, especially for young couples who are planning a family, who contrary to repeated media and scholarly pronouncements, may find solace that raising children may actually be related to feelings of engagement, meaning in life and happiness.

Author Contributions AS: Conceptualization, Study design, Data collection, Data analysis, Figures, Data interpretation, Literature search, Writing. SY: Study design, Data collection, Data analysis, Literature search, Writing.

Funding There was no funding for this study.

\section{Declarations}

Conflict of interest The authors have not conflict of interest to disclose.

Ethical Approval All procedures performed in studies involving human participants were in accordance with the ethical standards of the institutional and/or national research committee and with the 1964 Helsinki declaration and its later amendments or comparable ethical standards.

Informed Consent Informed consent was obtained from all the participants in the study.

\section{References}

Azar, S. T. (2002). Adult development and parenthood: A social-cognitive perspective. In J. Demick (Ed.) Handbook of adult development (pp. 391-415) Kluwer Academic. Boston

Barnett, R. C., \& Hyde, J. S. (2001). Women, men, work, and family: An expansionist theory. American Psychologist, 56(10), 781-796. https://doi.org/10.1037/0003-

Bianchi, S. M., \& Mattingly, M. J. (2003). Time, work, and family in the United States. Advances in Life Course Research, 8, 95-118. https://doi.org/10.1016/S1040-2608(03)08005-5

Bittman, M., \& Wajcman, J. (2000). The rush hour: The character of leisure time and gender equity. Social Forces, 79(1), 165-189. https://doi.org/10.1093/sf/79.1.165

Clarke-Stewart, A. (1979). Child care in the family. Academic Press.

Cohn, M. A., \& Fredrickson, B. L. (2010). In search of durable positive psychology interventions: Predictors and consequences of long-term positive behavior change. The Journal of Positive Psychology, 5(5), 355-366. https://doi.org/10.1080/17439760.2010.508883

Csikszentmihalyi, M. (1990). Flow: the psychology of optimal experience. Harper Perennial.

Csikszentmihalyi, M. (1997). Finding flow: The psychology of engagement with everyday life. Basic books.

Csikszentmihalyi, M., Abuhamdeh, S., \& Nakamura, J. (2014). Flow. In M. Csikszentmihalyi, Flow and the foundations of positive psychology (p. 238), Springer. 
Csikszentmihalyi, M., \& Csikszentmihalyi, I. S. (Eds.). (1992). Optimal experience: Psychological studies of flow in consciousness. Cambridge university press.

Csikszentmihalyi, M., \& LeFevre, J. (1989). Optimal experience in work and leisure. Journal of Personality and Social Psychology, 56(5), 815-822. https://doi.org/10.1037/0022-3514.56.5.815

Delle Fave, A., \& Massimini, F. (2004). Parenthood and the quality of experience in daily life: A longitudinal study. Social Indicators Research, 67(1-2), 75-106. https://doi.org/10.1023/B:SOCI.00000 07335.26602 .59

Delle Fave, A., Pozzo, M., Bassi, M., \& Cetin, I. (2013). A longitudinal study on motherhood and wellbeing: Developmental and clinical implications. Terapia Psicológica, 1(1), 21-33.

Diener, E. (2000). Subjective well-being: The science of happiness and a proposal for a national index. American Psychologist, 55(1), 34-43. https://doi.org/10.1037/0003-066X.55.1.34

Diener, E., \& Seligman, M. E. (2004). Beyond money: Toward an economy of well-being. Psychological Science in the Public Interest, 5(1), 1-31. https://doi.org/10.1111/j.0963-7214.2004.00501001.x

Diener, E. D., Emmons, R. A., Larsen, R. J., \& Griffin, S. (1985). The satisfaction with life scale. Journal of Personality Assessment, 49(1), 71-75. https://doi.org/10.1207/s15327752jpa4901_13

Dix, T. (1991). The affective organization of parenting: Adaptive and maladaptative processes. Psychological Bulletin, 110(1), 3-25. https://doi.org/10.1037/0033-2909.110.1.3

Doty, J. L., Davis, L., \& Arditti, J. A. (2017). Cascading resilience: Leverage points in promoting parent and child well-being. Journal of Family Theory \& Review, 9(1), 111-126. https://doi.org/10.1111/ jftr. 12175

Dow, G. K., \& Juster, F. T. (1985). Goods, time, and well-being: The joint dependence problem. In F. T. Juster \& F. P. Stafford (Eds.), Time, goods, and well-being (pp. 397-414). The University of Michigan.

Edin, K., \& Kefalas, M. (2011). Promises I can keep: Why poor women put motherhood before marriage. University of California Press.

Ekas, N. V., Lickenbrock, D. M., \& Whitman, T. L. (2010). Optimism, social support, and well-being in mothers of children with autism spectrum disorder. Journal of Autism and Developmental Disorders, 40(10), 1274-1284. https://doi.org/10.1007/s10803-010-0986-y

Fagan, J., Day, R., Lamb, M. E., \& Cabrera, N. J. (2014). Should researchers conceptualize differently the dimensions of parenting for fathers and mothers? Journal of Family Theory \& Review, 6(4), 390-405. https://doi.org/10.1111/jftr.12044

Faul, F., Erdfelder, E., Lang, A. G., \& Buchner, A. (2007). G* Power 3: A flexible statistical power analysis program for the social, behavioral, and biomedical sciences. Behavior Research Methods, 39(2), 175-191. https://doi.org/10.3758/BF03193146

Flood, L. (1997). Household, market and nonmarket activities. Procedures and codes for the 1993 time use survey. Uppsala University, Uppsala, Sweden.

Fredrickson, B. L. (2001). The role of positive emotions in positive psychology: The broaden-and-build theory of positive emotions. American Psychologist, 56(3), 218-226. https://doi.org/10.1037/0003066X.56.3.218

Fredrickson, B. L., \& Dutton, J. E. (2008). Unpacking positive organizing: Organizations as sites of individual and group flourishing. The Journal of Positive Psychology, 3(1), 1-3.

Galinsky, E., Aumann, K., \& Bond, J. T. (2009). Times are changing: Gender and generation at work and at home. Families and Work Institute.

Garey, A. I. (1999). Weaving work and motherhood. Temple University Press.

Gibaud-Wallston, J., \& Wandersman, L. P. (1978). Parenting sense of competence scale. Lawrence Erlbaum Associates.

Hart, S., \& Hodson, V. K. (2006). Respectful Parents, Respectful Kids: 7 Keys to Turn Family Conflict into Cooperation. PuddleDancer Press.

Kahneman, D., \& Krueger, A. B. (2006). Developments in the measurement of subjective well-being. Journal of Economic Perspectives, 20(1), 3-24. https://doi.org/10.1257/089533006776526030

Kahneman, D., Krueger, A. B., Schkade, D. A., Schwarz, N., \& Stone, A. A. (2004). A survey method for characterizing daily life experience: The day reconstruction method. Science, 306(5702), 17761780. https://doi.org/10.1126/science.1103572

Kerr, M. L., Rasmussen, H. F., Buttitta, K. V., Smiley, P. A., \& Borelli, J. L. (2020). Exploring the complexity of mothers' real-time emotions while caregiving. Emotion. Advance online publication. doi:https://doi.org/10.1037/emo0000719

Kline, R. B. (2010). Principles and practice of structural equation modeling (3rd ed.). Guilford Press.

Liss, M., Schiffrin, H. H., Mackintosh, V. H., Miles-McLean, H., \& Erchull, M. J. (2013). Development and validation of a quantitative measure of intensive parenting attitudes. Journal of Child and Family Studies, 22(5), 621-636. https://doi.org/10.1007/s10826-012-9616-y 
Lyubomirsky, S., \& Layous, K. (2013). How do simple positive activities increase well-being? Current Directions in Psychological Science, 22(1), 57-62. https://doi.org/10.1177/0963721412469809

Markowitz, E. S., Deutsch, N. L., \& Lawrence, E. C. (2014). Balancing skills and challenges: Exploring the concept of relational engagement in combined group and one-on-one mentoring for adolescent girls. In D. J. Shernoff \& J. Bempechat (Eds.), Engaging youth in schools: Evidence-based models to guide future innovations (pp. 146-164). NSSE Yearbooks by Teachers College Record.

Matusicky, C., \& Russell, C. C. (2009). Best practices for parents: What is happening in Canada? Paediatrics \& Child Health, 14(10), 664-665. https://doi.org/10.1093/pch/14.10.664

Mesurado, B., \& de Minzi, M. C. R. (2014). Optimal experience in Argentinean children and adolescents. In A. Castro Solano, (Ed.), Positive Psychology in Latin America (pp. 161-177). New York, NY: Springer

Milkie, M. A., Kendig, S. M., Nomaguchi, K. M., \& Denny, K. E. (2010). Time with children, children's well-being, and work-family balance among employed parents. Journal of Marriage and Family, 72(5), 1329-1343. https://doi.org/10.1111/j.1741-3737.2010.00768.x

Musick, K., Meier, A., \& Flood, S. (2016). How parents fare: Mothers' and fathers' subjective well-being in time with children. American Sociological Review, 81(5), 1069-1095. https://doi.org/10.1177/00031 22416663917

Negraia, D. V., \& Augustine, J. M. (2020). Unpacking the parenting well-being gap: The role of dynamic features of daily life across broader social contexts. Social Psychology Quarterly. https://doi.org/10. $1177 / 0190272520902453$

Nelson-Coffey, S. K., Killingsworth, M., Layous, K., Cole, S. W., \& Lyubomirsky, S. (2019). Parenthood is associated with greater well-being for fathers than mothers. Personality and Social Psychology Bulletin, 45(9), 1378-1390. https://doi.org/10.1177/0146167219829174

Nelson, S. K., Kushlev, K., \& Lyubomirsky, S. (2014). The pains and pleasures of parenting: When, why, and how is parenthood associated with more or less well-being? Psychological Bulletin, 140(3), 846895. https://doi.org/10.1037/a0035444

Nelson, S. K., Kushlev, K., English, T., Dunn, E. W., \& Lyubomirsky, S. (2013). In defense of parenthood: Children are associated with more joy than misery. Psychological Science, 24(1), 3-10. https://doi.org/ 10.1177/0956797612447798

Nicholson, J., Shimpi, P. M., Kurnik, J., Carducci, C., \& Jevgjovikj, M. (2014). Listening to children's perspectives on play across the lifespan: Children's right to inform adults' discussions of contemporary play. International Journal of Play, 3(2), 136-156. https://doi.org/10.1080/21594937.2014.937963

Nomaguchi, K., \& Milkie, M. A. (2017). Sociological perspectives on parenting stress: How social structure and culture shape parental strain and the well-being of parents and children. In K. D. Deater-Deckard \& R. Panneton (Eds.), Parental stress and early child development (pp. 47-73). Springer.

Rathunde, K. (1988). Optimal experience and the family context. Optimal Experience: Psychological Studies of Flow in Consciousness. https://doi.org/10.1017/cbo9780511621956.021

Robinson, M. D., \& Clore, G. L. (2002). Belief and feeling: Evidence for an accessibility model of emotional self-report. Psychological Bulletin, 128(6), 934-960. https://doi.org/10.1037/0033-2909.128.6. 934

Schwartz, S. J., \& Waterman, A. S. (2006). Flow experiences scale. PsycTESTS Dataset. https://doi.org/10. 1037/t10153-000

Senior, J. (2014). All joy and no fun: The paradox of modern parenthood. Hachette UK.

Sheldon, K. M., \& Lyubomirsky, S. (2012). The challenge of staying happier: Testing the hedonic adaptation prevention model. Personality and Social Psychology Bulletin, 38(5), 670-680. https://doi.org/10. 1177/0146167212436400

Shepherd, J., \& Roker, D. (2005). The parenting of young people: Using newsletters to provide information and support. Children \& Society, 19(4), 264-277. https://doi.org/10.1002/chi.832

Thompson, E. R. (2007). Development and validation of an internationally reliable short-form of the positive and negative affect schedule (PANAS). Journal of Cross-Cultural Psychology, 38(2), 227-242.

Umberson, D. (1989). Relationships with children: Explaining parents' psychological well-being. Journal of Marriage and the Family, 51(4), 999-1012. https://doi.org/10.2307/353212

Waters, L., \& Sun, J. (2016). Can a brief strength-based parenting intervention boost self-efficacy and positive emotions in parents? International Journal of Applied Positive Psychology, 1(1-3), 41-56. https:// doi.org/10.1007/s41042-017-0007-X

Watson, D., Clark, L. A., \& Tellegen, A. (1988). Development and validation of brief measures of positive and negative affect: The PANAS scales. Journal of Personality and Social Psychology, 54(6), 10631070. https://doi.org/10.1037/0022-3514.54.6.1063

Wells, A. J. (1988). Variations in mothers' self-esteem in daily life. Journal of Personality and Social Psychology, 55(4), 661-668. https://doi.org/10.1037/0022-3514.55.4.661 
Winnicott, D. W. (1960). The theory of the parent-infant relationship. International Journal of Psychoanalysis, 41(6), 585-595.

Winnicott, D. W. (1971). Playing and reality. Psychology Press.

Wolfe, M. W. (2006). Mother and child: A multi-determinant model for maternal and infant health outcomes in urban, low-income communities and the effectiveness of prenatal care and other interventions. Journal of Public \& International Affairs, 17, 169-189.

Yavorsky, J. E., Kamp Dush, C. M., \& Schoppe-Sullivan, S. J. (2015). The production of inequality: The gender division of labor across the transition to parenthood. Journal of Marriage and Family, 77(3), 662-679. https://doi.org/10.1111/jomf.12189

Yeung, W. J., Sandberg, J. F., Davis-Kean, P. E., \& Hofferth, S. L. (2001). Children's time with fathers in intact families. Journal of Marriage and Family, 63(1), 136-154. https://doi.org/10.1111/j.1741-3737. 2001.00136.x

Publisher's Note Springer Nature remains neutral with regard to jurisdictional claims in published maps and institutional affiliations. 